\title{
En los límites de la exclusión social. Inmigración y sinhogarismo en España
}

\author{
Ma Rosario Hildegard Sánchez Morales
}

Universidad Nacional de Educación a Distancia. Grupo de Estudio sobre Tendencias Sociales msanchez@poli.uned.es

\section{Resumen}

La cuestión migratoria es uno de los fenómenos que tiene mayor relevancia a principios del siglo xxi. España, históricamente emisora de emigrantes, se ha convertido, en menos de una década, en un país de destino que ha ido acogiendo a personas procedentes de áreas geográficas y culturales muy alejadas de nuestras tradiciones. En los dos últimos años, la población inmigrante está sufriendo especialmente los efectos de la crisis económica, con lo que se ha puesto de manifiesto su extrema vulnerabilidad social. Uno de los efectos más significativos ha sido su reciente incorporación al colectivo de personas "sin hogar», al tiempo que otros no consiguieron, a lo largo de los años, normalizar sus vidas en nuestra sociedad y fueron derivando hacia la exclusión social más extrema. Vamos a ofrecer los resultados obtenidos en una investigación sobre "sinhogarismo» iniciada en el año 1998 con continuidad por el Grupo de Estudio sobre Tendencias Sociales (GETS) de la UNED, además, incluimos algunos datos obtenidos en el Quinto recuento nocturno sobre personas «sin hogar» realizado en la ciudad de Madrid en el año 2010 e informaciones de memorias de actividad de recursos dispuestos por toda la geografía española para atender a sus necesidades. Las principales conclusiones de este texto son que la internacionalización de la exclusión social extrema en España es una realidad y se prevé que esta problemática puede incrementarse en los próximos años.

Palabras clave: inmigración; exclusión social; personas sin techo.

\section{Abstract. On the boundaries of social exclusion: Immigration and homelessness in Spain}

Immigration is one of the most important phenomena occurring in the early 21 st century. In less than one decade, Spain has gone from being a sender of emigrants to become a major destination for immigrants, receiving people from geographical areas and cultural backgrounds that differ greatly from our traditions. In the last two years, the immigrant population has most suffered the effects of the economic crisis, revealing their extreme social vulnerability. The most significant of these effects has been the rise in homelessness among immigrants and the fact that many immigrants have been unable to normalize their situation in Spanish society and suffer extreme social exclusion. In this paper, we show the results obtained in an ongoing investigation on homelessness that was first begun in 
1998 by the Study Group on Social Trends (GETS) of the National Distance University (UNED). We also provide data from the Fifth Inventory on the Homeless conducted in Madrid in 2010, and information from reports on the resources available throughout Spain to attend to the needs of homeless people. The principal conclusions are that the internationalization of extreme social exclusion is a reality in Spain and that this problem is likely to worsen in coming years.

Keywords: immigration; social exclusion; homeless.

\section{Sumario}

$\begin{aligned} \text { Introducción } & \begin{array}{l}\text { Factores de vulnerabilidad y exclusión } \\ \text { social entre los inmigrantes «sin hogar» }\end{array} \\ \text { La inmigración en España } & \text { La población inmigrante en situación } \\ \text { Inmigración y exclusión social } & \text { de exclusión social extrema } \\ \text { Inmigrantes «sin hogar»versus } & \text { Referencias bibliográficas } \\ \text { inmigrantes «sin techo» } & \end{aligned}$

\section{Introducción}

La cuestión migratoria se ha convertido en uno de los fenómenos de mayor relevancia a principios del siglo XxI. Desde Europa, pasando por América y Asia, nos enfrentamos a un proceso migratorio de alcance planetario de gran complejidad. Según Naciones Unidas (United Nations, 2009), existen 213.943.812 millones de migrantes internacionales. Además, el número de inmigrantes se ha duplicado en los últimos veinticinco años y más de la mitad se ha dirigido hacia Europa y América del Norte.

El modelo migratorio actual no se ajusta a las motivaciones vivenciales de los ciudadanos de otros momentos históricos. Las imágenes de principios del siglo xx, recogidas en los documentales históricos de la época, en los que se observa a familias europeas esperando en las dependencias de puertos norteamericanos para entrar para siempre en el que ya sería su país por generacio$n^{1}{ }^{1}$, han dejado paso, en nuestro siglo, a imágenes distintas. Desde comienzos del siglo Xxi, los medios de comunicación internacionales nos muestran una realidad migratoria vinculada a otra realidad.

El hambre, las guerras, la enfermedad, las desigualdades, la pobreza, la inseguridad política, en definitiva, la falta de expectativas de futuro son las causas fundamentales subyacentes a los procesos migratorios de nuestros días ${ }^{2}$. Según el último Informe de desarrollo humano (PNUD, 2011), de un total de

1. Para entender la naturaleza de los procesos migratorios de principios del siglo $\mathrm{xx}$, resulta muy ilustrativa la clásica obra de William I. Thomas y Florian Znaniecki, El campesino polaco en Europa y América (Thomas y Znaniecki, 2004).

2. Para contextualizar en profundidad el tema y adentrarse en los efectos de la inmigración en los países de recepción, véase José Félix Tezanos (2007), Carlota Solé y Emilio Reyneri (2001) y José Félix Tezanos y Alfonso Guerra (ed.) (2008). 
109 países analizados, se estima que cerca de 1.700 millones de personas, es decir, un tercio de su población, han sufrido pobreza multidimensional durante 2000 y $2010^{3}$. Además, existen unos 215 millones de niños, con edades comprendidas entre los cinco y los diecisiete años, que están trabajando, de entre los cuáles 115 millones desempeñan actividades laborales de alta peligrosidad (OIT, 2011). Por último, consignar que, según la FAO, el número de personas hambrientas ascendió en 2010 a 925 millones. No existen datos elaborados relativos al año 2011 (FAO, 2011).

Considerando estas circunstancias, en situación extrema se encuentra el continente africano y Asia, pero también se observan importantes carencias en América del Sur y Central.

\section{La inmigración en España}

España, históricamente emisora de emigrantes, se ha convertido en una década en un país receptor, hasta tal punto que, tras los Estados Unidos, fue el segundo que más inmigrantes recibió en números absolutos en el año 2004

Tabla 1. Evolución de la población extranjera censada en España

\begin{tabular}{lcc}
\hline Año & Extranjeros censados & $\%$ del total de población \\
\hline 1981 & 198.043 & $0,52 \%$ \\
1986 & 241.971 & $0,63 \%$ \\
1991 & 360.655 & $0,91 \%$ \\
1996 & 542.314 & $1,37 \%$ \\
1998 & 637.085 & $1,60 \%$ \\
2000 & 923.879 & $2,28 \%$ \\
2001 & 1.370 .657 & $3,33 \%$ \\
2002 & 1.977 .657 & $4,73 \%$ \\
2003 & 2.664 .168 & $6,24 \%$ \\
2004 & 3.034 .326 & $7,02 \%$ \\
2005 & 3.730 .610 & $8,46 \%$ \\
2006 & 4.144 .166 & $9,27 \%$ \\
2007 & 4.519 .554 & $9,93 \%$ \\
2008 & 5.268 .762 & $11,41 \%$ \\
2009 & 5.648 .671 & $12,80 \%$ \\
2010 & 5.730 .667 & $12,22 \%$ \\
\hline
\end{tabular}

Fuente: INE, padrones municipales de varios años.

3. El índice de pobreza multidimensional complementa a los índices basados en medidas monetarias y toma en consideración las privaciones que experimentan las personas pobres, así como el marco en que éstas tienen lugar. Los componentes del índice de pobreza multidimensional son: salud (nutrición y mortalidad infantil), educación (años de instrucción, matriculación escolar) y niveles de vida (combustible para cocinar, saneamiento, agua, electricidad, piso y bienes). 
(Izquierdo, 2007: 77-100; Carrasco e Izquierdo, 2005: 92-122; López de Lera e Izquierdo, 2000: 181-200). La población extranjera se ha cuadriplicado en lo que va del siglo xxi. En el año 2001, los extranjeros censados ascendieron a 360.655; en 2010, la cifra de extranjeros fue de 5.730.667 personas (12,22\% del total de la población) (véase la tabla 1), si bien en 2011 se ha producido por primera vez una disminución en el número de efectivos $(-0,3 \%)$ (INE, 2011c).

Dos son, fundamentalmente, las zonas geográficas de procedencia de los inmigrantes que han venido en la última década a nuestro país: Europa Oriental y Latinoamérica (véase la tabla 2).

Los procedentes de Europa Oriental son, en estos momentos, básicamente ciudadanos de Rumanía $(15,1 \%)$, la colonia extranjera más numerosa desde hace varios años en nuestro país (INE, 2011). El grueso de inmigrantes de los países latinoamericanos proviene de Ecuador $(6,3 \%)$ y de Colombia $(4,7 \%)^{4}$ (INE, 2011c).

La tercera zona geográfica exportadora de emigrantes a escala mundial es África subsahariana, aunque su presencia en nuestras fronteras resulte cuantitativamente minoritaria. Ahora bien, España se ha convertido en un país de acogida, por ser la puerta de Europa para estos jóvenes, aunque se observa en los dos últimos años un aminoramiento de las llegadas de cayucos y pateras (véase la tabla 2).

Hay una cuarta zona de salida de población inmigrante en la actualidad en el mundo, es la de Asia, cuya incidencia estadística en nuestro país es poco significativa, salvo la colonia china (2,9\%) y la pakistaní $(1,2 \%)^{5}$ (INE, 2011c).

De forma que los datos revelan que España se ha convertido, en pocos años, en un país de destino que ha ido acogiendo a personas procedentes

Tabla 2. Población extranjera en España por grupos de países (2011)

\begin{tabular}{lrc}
\hline Países de origen & Población & $\%$ respecto al total de inmigrantes en España \\
\hline EU-27 & 2.392 .491 & $41,7 \%$ \\
Resto Europa & 234.760 & $4,1 \%$ \\
África & 1.078 .899 & $18,8 \%$ \\
América del Norte & 54.547 & $0,9 \%$ \\
América Central y Caribe & 206.329 & $3,6 \%$ \\
América del Sur & 1.418 .751 & $24,8 \%$ \\
Asia & 341.886 & $6 \%$ \\
\hline
\end{tabular}

Fuente: elaboración propia a partir del INE, Padrón municipal, 4 de abril de 2011.

4. En el año 2010, los mayores decrecimientos en términos absolutos se han producido entre los ciudadanos de Ecuador (-40.510) y de Colombia (-20.868).

5. Precisamente, los mayores incrementos relativos entre las nacionalidades con mayor número de empadronados corresponden a ciudadanos de Pakistán $(22,8 \%)$ y China $(5,0 \%)$ (INE, $2011 \mathrm{c})$. 
de áreas geográficas y culturales diversas. La historia nos demuestra que los principios de siglo son etapas de grandes cambios sociales. El siglo XXI se anticipa lleno de extraordinarios avances científico-tecnológicos ${ }^{6}$, junto a ello, millones de personas se han visto en la necesidad de salir de sus países, si bien su integración (Noya e Izquierdo, 1999: 19-42) en los países receptores no siempre se alcanza. En los dos últimos años, la población inmigrante asentada en nuestro país está sufriendo especialmente los efectos de la crisis, y se ha puesto de manifiesto su extrema vulnerabilidad en fases económicas de recesión como la actual. Algunos de ellos se están incorporando al mundo de las personas «sin hogar». A este perfil hay que añadir el de los inmigrantes que no consiguieron normalizar sus vidas en nuestra sociedad a lo largo de los años y fueron derivando su existencia hacia la exclusión social más extrema. La red de atención a personas «sin hogar» en España pone de manifiesto los déficits de integración de la población inmigrante., de forma que las nacionalidades de los allí atendidos se corresponden, básicamente, con las principales nacionalidades de procedencia.

En orden a profundizar en este tema, en el presente texto vamos a ofrecer los resultados obtenidos en una investigación sobre sinhogarismo iniciada en el año 1998 con continuidad por el Grupo de Estudio sobre Tendencias Sociales (GETS) de la UNED, que, hasta la fecha, ha realizado 135 entrevistas a informantes clave en diversas ciudades españolas (Madrid, Granada y Barcelona), así como dos grupos de discusión con personas «sin hogar» que residían en albergues y dos grupos de discusión con voluntarios que atienden en esta población. Se han realizado 80 entrevistas a personas «sin hogar», tanto en la calle como en centros de acogida en Madrid y Barcelona, 25 a mujeres y 55 a varones ${ }^{7}$. Se ha incorporado, además, la variable edad y origen, españoles ( 40 entrevistas) versus extranjeros ( 40 entrevistas). Por otro lado, se ha entrevistado a un total de 50 profesionales, tanto en Madrid como en Barcelona y Granada, cuyo trabajo está directamente relacionado con la gestión pública de programas de atención para esta población, así como a responsables de centros de acogida, albergues y a voluntarios de ONGs que colaboran con programas de atención para esta población. Además, se ha consultado a un total de 5 académicos especializados en el tema, que, a largo de década y media de investigación, han ido aportando diversas informaciones sobre esta realidad cambiante.

Las citas literales de los entrevistados y de los participantes en los grupos de discusión se recogen en el texto entre comillas. Asimismo, ofreceremos

6. Para profundizar en el ámbito de las tendencias científico-tecnológicas, véase GETS (1997, 2003, 2006).

7. En su mayor parte, las personas «sin hogar» son varones. El abanico porcentual de mujeres, según diversos estudios realizados en España, se sitúa entre el $9 \%$ y el 16\%. Para profundizar en este tema, véase Cabrera (2000), Sánchez Morales (1999: 166-172), Luque Salceda (2003: 249-264) y EDIS (2004: 7-11) . En orden a esta realidad, en el presente texto nos hemos centrado en mostrar el sinhogarismo teniendo en cuenta que se trata de un fenómeno masculinizado. 
algunos datos obtenidos en el Quinto recuento nocturno sobre personas «sin hogar» realizado en la ciudad de Madrid el 24 de febrero del año $2010^{8}$, así como de algunos dispositivos para personas «sin hogar» dispuestos por toda la geografía española.

\section{Inmigración y exclusión social}

La mayoría de los inmigrantes, a su llegada a nuestro país, se han encontrado en una situación de alto riesgo social. Variables tan elementales como ser blanco o negro, cristiano o musulmán, mujer u hombre han condicionado sus posibilidades de normalización. Si a lo anterior añadimos, en buena parte de los casos, la desorientación en las primeras fases al arribar, su situación de sin papeles, las dificultades de acceso al trabajo y a viviendas dignas, su posible falta de redes sociales de apoyo, el desconocimiento del idioma, de los modos de vida, el racismo biológico-cultural al que han podido verse sometidos, así como la insuficiencia de recursos de atención adecuados a sus necesidades, sus comienzos fueron particularmente difíciles.

Estas circunstancias han sido especialmente consignables entre los jóvenes que proceden del África subsahariana, cuyo perfil sociológico a su llegada obedece al de varones jóvenes" ${ }^{9}$ muchos de los cuales, al llegar a nuestro país «[...] se dan cuenta del error que han cometido y piensan que si hubieran sabido de antemano lo que pasarían en la patera, que dormirían en la calle [...] no hubieran venido [...] De hecho, hay gente que pide si se les puede pagar el billete para regresar [...]». Es decir, se ha generado una bolsa de exclusión social integrada por población inmigrante, una de cuyas derivaciones es la cada vez mayor presencia de extranjeros que han hecho de la calle y de los recursos de atención para población "sin hogar» sus espacios de vida. Se han convertido en personas desarraigadas, solitarias, sin expectativas de futuro y con una problemática profunda de desestructuración personal.

Para observarlo, basta con pasear por ciudades como Madrid o Barcelona, principales polos de atracción de los inmigrantes en España (INE, 2011c). Estas urbes se han convertido en espacios públicos de especial interés sociológico para los ciudadanos y estudiosos de la inmigración y la exclusión social. Frecuentar determinadas zonas de estas ciudades es un ejercicio que permite comprender in situ el alcance del fenómeno migratorio y su vinculación con

8. Estos recuentos se han organizado a instancia del Foro Técnico Local sobre Personas Sin Hogar en Madrid, creado por el alcalde Alberto Ruíz Gallardón, con fecha de 28 de diciembre de 2004. Se formalizó el Programa de Investigación Permanente sobre el sinhogarismo en el municipio de Madrid, coordinado por el profesor Pedro Cabrera, el profesor Manuel Muñoz y la profesora Ma Rosario Sánchez Morales. Entre las diversas actividades que ha organizado, se cuenta la realización, desde el año 2006, de cinco recuentos nocturnos sobre personas «sin hogar».

9. Por hacernos una idea de la envergadura del problema, según datos ofrecidos en el Informe de desarrollo humano de 2009, se calcula que más de 3.000 personas fallecieron ahogadas entre 1997 y 2005 en el estrecho de Gibraltar mientras intentaban llegar ilegalmente a Europa en embarcaciones precarias (PNUD, 2009: 12). 
la exclusión social ${ }^{10}$.

Casos que ilustran este binomio en sus diversas gradaciones son, por ejemplo, los jóvenes subsaharianos dedicados a la venta del top manta, que se relacionan con sus compatriotas y no se observa en ellos deterioro mental o físico, pero también comienzan a ser habituales, en plazas y lugares públicos de grandes ciudades españolas, grupos de extranjeros que, por su aspecto desaliñado, por tener determinadas adicciones y por cómo se muestran públicamente, se encuentran inmersos en procesos de exclusión social.

La pregunta de investigación, hilo conductor de este artículo, es: "¿A qué obedece el fenómeno de la internacionalización del sinhogarismo?». A partir de esta cuestión, los objetivos que nos hemos planteado son: exponer la nomenclatura utilizada para señalizar a estas personas, mostrar los principales factores exclusógenos que se observan en los itinerarios vitales de los inmigrantes que acaban en situación de sinhogarismo, ofrecer datos que verifiquen la internacionalización de este fenómeno en nuestro país y trazar algunas pinceladas sobre su futuro previsible, teniendo en cuenta la percepción de las propias personas «sin hogar» y de la opinión pública española.

\section{Inmigrantes «sin hogar» versus inmigrantes «sin techo»}

En los trabajos del GETS, utilizamos la terminología de persona «sin hogar», diferenciándola de la persona «sin techo», por entender que es la conceptualización que mejor se acerca a las vidas y al desarraigo social que caracteriza a los seres humanos que se desenvuelven dentro de la exclusión social extrema.

En la bibliografía especializada, se emplean indistintamente los conceptos de persona «sin hogar» o persona "sin techo» «[...] para referirse a los ciudadanos que se han ido quedando fuera de las oportunidades vitales que definen una ciudadanía social plena en las sociedades de nuestros días» (Tezanos, 1998: 11). También términos como los de «mendigo», "vagabundo», «indigente» $\mathrm{y}$ «transeúnte» suelen ser manejados por los medios de comunicación e incluso por los profesionales de Servicios Sociales para referirse a fenómenos sociológicos que responden a otras realidades.

Los conceptos de persona «sin techo» y persona «sin hogar» comparten la perspectiva de tratarse del grupo social que vive sin un techo. Pero una comprensión de su problemática obliga a ir más allá de la exclusión que padecen, en el sentido de la falta de un espacio físico digno en el que vivir ${ }^{11}$. Bajo este

10. De igual modo, en Europa, la internacionalización del sinhogarismo es una realidad, tal como se refleja en las publicaciones de FEANTSA $(2010,2004)$ y Edgar, Doherty y Meert (2004).

11. La European Federation of National Organisations Working with the Homeless (FEANTSA) establece una tipología europea de las personas sin hogar y la exclusión residencial:

a) Estar sin techo (roofless):

1. Vivir en un espacio público (sin domicilio).

2. Pernoctar en un albergue y/o forzado a pasar el resto del día en un espacio público. 
abanico, se esconden diversas opciones, desde la de aquellos que se encuentran literalmente en la calle, hasta las variantes de precariedad residencial, es decir, el chabolismo o el hacinamiento en el que viven muchos inmigrantes. Dicho fenómeno afecta a unas veinticinco mil personas en España, de las cuales aproximadamente diez mil viven literalmente en la calle.

Iniciarse en el sinhogarismo conlleva la vivencia de un proceso progresivo de pérdida del nicho afectivo, social y personal en el que desarrollarse y proyectarse como seres humanos. Además, estas personas van perdiendo la motivación, la autoestima, y no disfrutan plenamente de derechos sociales, máxime en el caso de los inmigrantes «sin papeles». Queremos destacar las carencias y el déficit que pueden llegar a padecer en el plano convivencial, relacional, familiar, personal, asistencial y cultural, que, en último término, puede conducirles al desarraigo y a la indigencia social.

Las personas «sin hogar» son personas «sin techo», no tienen un espacio donde vivir, pero ese no es su único problema. Sin embargo, los «sin techo» no son necesariamente personas «sin hogar». Esta reflexión es especialmente pertinente a la hora de hacer un análisis sobre los inmigrantes a su llegada a nuestro país y que no cuentan con redes sociales de apoyo. Ha sido un perfil habitual en los recursos de atención para población «sin hogar» dispuestos por la geografía española. En un sentido amplio, todos los inmigrantes, en mayor o menor medida, encuentran dificultades a la hora de acceder a lugares en los que poder vivir dignamente. Son, en definitiva, personas «sin techo", pero no necesariamente personas «sin hogar».

Dentro del fenómeno del sintechismo entre los inmigrantes, cabe establecer tipologías, desde aquellos que viven literalmente en la calle o recurren a los albergues, los centros de acogida o los dispositivos de alojamiento de emergencia, hasta los que viven en infraviviendas, bajo condiciones de hacinamiento o en casa de amigos o familiares. Pero, además, comienzan a detectarse extranjeros en situación de sinhogarismo crónico.

b) Estar sin vivienda (houseless):

3. Estancia en centros de servicios o refugios (hostales para «sin techo» que permiten diferentes modelos de estancia).

4. Vivir en refugios para mujeres.

5. Vivir en alojamientos temporales reservados a los inmigrantes y a los demandantes de asilo.

6. Vivir en instituciones: prisiones, centros de atención sanitaria, hospitales sin tener a donde ir, etc.

7. Vivir en alojamientos de apoyo (sin contrato de arrendamiento).

c) Vivienda insegura (insecure housing):

8. Vivir en una vivienda sin título legal (vivir temporalmente con familiares o amigos de forma involuntaria, vivir en una vivienda sin contrato de arrendamiento - se excluyen los ocupas-, etc.).

9. Notificación legal de abandono de la vivienda.

10. Vivir bajo la amenaza de violencia por parte de la familia o de la pareja.

d) Vivienda inadecuada:

11. Vivir en una estructura temporal o chabola.

12. Vivir en una vivienda no apropiada según la legislación estatal.

13. Vivir en una vivienda masificada. 
Así las cosas, visitar, por ejemplo, los dispositivos de atención de la Campaña Municipal contra el Frío de la ciudad de Madrid en una noche cualquiera de invierno permite comprender la diferencia entre el «sin hogar» y el «sin techo». El joven inmigrante, con aspecto saludable y aseado, vestido correctamente, que se comunica con sus compatriotas, que acude en compañía de amigos y a primera hora de la mañana se arregla, desayuna y sale a buscar trabajo no es asimilable con el «sin hogar» que también acude a este mismo lugar. El «sin hogar» responde al perfil de una persona desestructurada, con un aspecto deteriorado e incluso sucio, mal vestido, con mala salud, algunos también con problemas de consumo de alcohol o sustancias psicoactivas, que sufren dificultades de comunicación, que no tienen prisa por irse y pasan el día deambulando de un lugar a otro. En estos tres últimos años, a consecuencia de la crisis económica, que ha afectado con especial dureza a los inmigrantes ${ }^{12}$, se observa un cambio en el perfil de los usuarios de estos recursos. Son mayoritariamente extranjeros, con un nivel de desestructuración y desarraigo muy acusados. Muchos de ellos se han convertido, en definitiva, en personas «sin hogar», en el sentido profundo del término.

Una presentación de estas características nos sitúa en el marco analítico de los estudios de exclusión social, que enfoca los itinerarios de vida de los individuos y colectivos más vulnerabilizados en las sociedades más avanzadas en términos procesuales, asociados a la interconexión de una multiplicidad de factores (Tezanos, 2001: 140-147).

\section{Factores de vulnerabilidad y exclusión social entre los inmigrantes «sin hogar»}

La vulnerabilidad en la que se han encontrado la mayoría de los inmigrantes que han venido a nuestro país ha sido determinante en sus procesos hacia la exclusión social. Procesos vinculados a la interrelación de factores estructurales, familiares i/o relacionales, personales y culturales, en el sentido de una progresiva fragilización de sus anclajes sociales. Tras experiencias vitales marcadas por la vivencia de sucesos traumáticos (Muñoz, Vázquez y Vázquez, 2003: 19) ${ }^{13}$, algunos acaban en una situación de sinhogarismo, con pocas posibilidades de autonomización personal, si bien existen diversos grados de desarraigo y desestructuración personal. Es necesario plantear este matiz, pues, en función de las características personales de cada individuo, se articulan los mecanismos de intervención, que pueden ir desde la prevención, en las primeras fases de

12. Según datos de la Encuesta de población activa del primer trimestre de 2012, la tasa de paro entre la población extranjera es casi 15 puntos superior de la que tienen las personas de nacionalidad española.

13. Existen algunos estudios que demuestran que las personas «sin hogar» padecen un número más elevado de experiencias traumáticas que las personas que viven en situación de normalidad. En una investigación realizada en Madrid hace unos años, se demostró que las personas «sin hogar» sufren, a lo largo de su vida, una media de nueve sucesos estresantes. Véase Muñoz, Vázquez y Vázquez (2003: 19). 
desarraigo, hasta la reducción de daños en procesos de acompañamiento social, cuando ya se encuentran en un nivel avanzado de exclusión social.

En concreto, ¿qué variables y factores pueden convertir a un joven inmigrante, sano, con ilusiones y expectativas de futuro en una persona «sin hogar» crónica? Resultan ilustrativas las palabras de un profesional consultado por el GETS, quien planteaba que «[...] muchos inmigrantes llegan aquí engañados por las mafias que les traen y que les cobran hasta trescientos euros al mes [...], llegan con un estado físico, moral y mental relativamente bueno [...] pero se encuentran con lo que se encuentran [...] Y luego viene el deterioro, viene ese bajón de venir y no poder acceder a trabajos, a viviendas [...], no pueden arreglar los papeles [...] están y duermen en la calle [...] Y entonces muchos empiezan a entrar en depresión [...], pues el proceso de continuar en esa situación sí puede afectar a esa persona a deteriorarse [...] y, pasado el tiempo, se convierten en personas «sin hogar». Es por estas circunstancias por las que consideran que hubieran necesitado «[...] un apoyo de acogida, de orientación [...] y si no se ofrece se corre el riesgo de que la persona se vaya deteriorando y pueda convertirse en un desarraigado, en una persona "sin hogar". Esta ha sido una de las vías de entrada al sinhogarismo entre la población inmigrante» (Bosch-Meda, 2010: 139-154).

Los datos revelan que la zona geográfica de procedencia ha condicionado, en buena medida, las posibilidades de normalización i/o integración en la sociedad española ${ }^{14}$.

La inmigración latinoamericana es, en principio, la que ha tenido mayores posibilidades de integración en la sociedad española, a pesar de que emigrar sea en sí mismo un suceso estresante. Se decidieron por venir a un país en donde conocían el idioma y culturalmente se podían desenvolver. Muchos de ellos, cuando llegaron a España, disponían de redes sociales de apoyo y tuvieron oportunidades laborales ${ }^{15}$. Resultó más complicada la normalización para los primeros de una familia o de un grupo de amigos. Los locutorios públicos, como espacios de comunicación transoceánicos y de contacto con compatriotas, han cumplido una función social de integración digna de aprecio. También los negocios étnicos han permitido que compartieran experiencias y mantuvieran vivas las relaciones personales y sus rasgos identitarios ${ }^{16}$.

Para los procedentes del África subsahariana, la situación de partida fue más compleja y la realidad es que no han tenido oportunidad de integrarse en la sociedad española. El denominador común entre la población inmigrante africana «[...] es que deciden salir de su país porque allí no pueden vivir, sea por guerra, por violencia, por persecución, por situación de hambruna». Los viajes suelen ser una experiencia negativa, pues «[...] hay gente que les puede llevar meses y años

14. Muy ilustrativas resultan en este sentido las publicaciones de Lurbe y Solé (2006) y Cavalcanti (2008).

15. Una encuesta realizada en el año 2007 por el GETS en los inicios de la crisis económica puso de manifiesto que, entre los latinoamericanos, la tasa de paro ascendía al 14\%, a diferencia de lo que sucedía con los africanos (27,5\%) (GETS, 2008: 59-60).

16. Véase el trabajo de Solé y Parella (2005). 
el llegar a España» y pueden verse obligados a vivir experiencias límite. Tras la vivencia de sucesos tan estresantes, como puede ser ver morir en el desierto o en cayucos a compañeros de viaje, se han de enfrentar a una realidad que no era la que imaginaban. Algunos contaban con redes de apoyo, pero tuvieron dificultades de acceder a trabajos, a viviendas. Por otro lado, la comunicación con sus familiares en sus países no ha sido fácil. Lo que ha sucedido es que, con el tiempo, muchos perdieron el contacto. Otros factores que jugaron en su contra fueron su bajo nivel de estudios ${ }^{17}$, su desconocimiento del idioma, de las costumbres y el choque cultural al que se enfrentaron en las primeras fases de su llegada. No obstante, muchos «salieron adelante» a través de trabajos en sectores ocupacionales como la agricultura, la construcción, los servicios y el comercio ambulante, caracterizados por bajos salarios y condiciones laborales precarias ${ }^{18}$.

En lo que se refiere a la emigración de las personas que proceden de los antiguos Países del Este, muchas de ellas salieron en situación de fuerte empobrecimiento. En general, los varones disponían de cualificación laboral ${ }^{19}$ (a excepción de los rumanos), tamibén de estudios y, a pesar de que desconocían el idioma y procedían de culturas disimilares a la nuestra, se iniciaron más satisfactoriamente en nuestro país. Por otro lado, disfrutaban de mayores facilidades para comunicarse con sus familiares. Asimismo, contaban con redes de apoyo a su llegada y con espacios vivenciales, como los locutorios y las tiendas étnicas. Las mujeres trabajan, generalmente, en el servicio doméstico, y la coadaptación entre éstas y las familias españolas ha sido pausada. Estas mejores facilidades de partida para su integración no han sido eximentes para que, entre las personas que acuden a los recursos para población «sin hogar», haya hombres y mujeres procedentes de estos países. No en vano, en el último año, la rumana es la nacionalidad principal de los usuarios de estos dispositivos.

Algunos iniciaron su exclusión más extrema en España, otros partían de una situación problematizada en sus lugares de origen. Se ha detectado un fenómeno de exportación del sinhogarismo entre los inmigrantes procedentes de la Europa Oriental.

En este sentido, cabe diferenciar entre los inmigrantes diversas situaciones de partida en sus países de origen, que pueden condicionar su normalización en sociedades receptoras como la española (véase la tabla 3).

En cualquier caso, tanto si nos centramos en los inmigrantes procedentes de Latinoamérica, del continente africano o de la esfera de los países del antiguo

17. Según la Encuesta nacional de inmigrantes, los inmigrantes con menor nivel de estudios son los procedentes de África. Casi la mitad de los inmigrantes de este origen no tienen estudios o han alcanzado un nivel de educación primaria (INE, 2008).

18. En la precitada encuesta del GETS de 2007, se puso de manifiesto que el paro ha afectado particularmente a los africanos en comparación con el resto de extranjeros $(27,5 \%)$. Este dato puso de manifiesto la existencia de una discriminación cultural en el mercado laboral de nuestro país hacia un grupo concreto de inmigrantes (GETS, 2008: 59-60).

19. Esa mayor cualificación tuvo su reflejo en que la tasa de paro entre los ciudadanos procedentes de los países europeos no miembros de la Unión Europea de los 15 ascendiera, en 2007, al 16\%, lejos de las circunstancias de los africanos (GETS, 2008: 59-60). 
Tabla 3. Diversas situaciones vitales de los inmigrantes en sus países de origen y posibles fases vitales en los países receptores

\begin{tabular}{|c|c|c|c|}
\hline $\begin{array}{l}\text { Situación vital en } \\
\text { el país de origen }\end{array}$ & $\begin{array}{c}\text { Primera fase vital a la llegada } \\
\text { al país receptor }\end{array}$ & $\begin{array}{l}\text { Segunda fase vital } \\
\text { en el país receptor }\end{array}$ & $\begin{array}{l}\text { Tercera fase vital en } \\
\text { el país receptor }\end{array}$ \\
\hline Normalizada & $\begin{array}{l}\text { Vulnerabilidad } \\
\text { (sintechismo) }\end{array}$ & $\begin{array}{l}\text { Exclusión } \\
\text { (fase avanzada) }\end{array}$ & $\begin{array}{l}\text { Exclusión extrema } \\
\text { sinhogarismo }\end{array}$ \\
\hline Normalizada & $\begin{array}{l}\text { Exclusión } \\
\text { (fase leve) }\end{array}$ & $\begin{array}{l}\text { Exclusión } \\
\text { (fase avanzada) }\end{array}$ & $\begin{array}{l}\text { Exclusión extrema } \\
\text { sinhogarismo }\end{array}$ \\
\hline Normalizada & $\begin{array}{l}\text { Vulnerabilidad } \\
\text { (sintechismo) }\end{array}$ & Pseudonormalización & $\begin{array}{l}\text { Normalización y/o } \\
\text { integración }\end{array}$ \\
\hline Vulnerabilizada & $\begin{array}{l}\text { Vulnerabilidad } \\
\text { (sintechismo) }\end{array}$ & $\begin{array}{l}\text { Exclusión } \\
\text { (fase avanzada) }\end{array}$ & $\begin{array}{l}\text { Exclusión extrema } \\
\text { sinhogarismo }\end{array}$ \\
\hline Vulnerabilizada & $\begin{array}{l}\text { Exclusión } \\
\text { (fase leve) }\end{array}$ & $\begin{array}{l}\text { Exclusión } \\
\text { (fase avanzada) }\end{array}$ & $\begin{array}{l}\text { Exclusión extrema } \\
\text { Sinhogarismo }\end{array}$ \\
\hline Vulnerabilizada & $\begin{array}{l}\text { Vulnerabilidad } \\
\text { (sintechismo) }\end{array}$ & Pseudonormalización & $\begin{array}{l}\text { Normalización y/o } \\
\text { integración }\end{array}$ \\
\hline Exclusión & $\begin{array}{l}\text { Vulnerabilidad } \\
\text { (sintechismo) }\end{array}$ & $\begin{array}{l}\text { Exclusión } \\
\text { (fase avanzada) }\end{array}$ & $\begin{array}{l}\text { Exclusión extrema } \\
\text { sinhogarismo }\end{array}$ \\
\hline Exclusión & $\begin{array}{l}\text { Exclusión } \\
\text { (fase avanzada) }\end{array}$ & $\begin{array}{l}\text { Exclusión } \\
\text { (fase avanzada) }\end{array}$ & $\begin{array}{l}\text { Exclusión extrema } \\
\text { sinhogarismo }\end{array}$ \\
\hline $\begin{array}{l}\text { Exclusión } \\
\text { extrema } \\
\text { (sinhogarismo) }\end{array}$ & $\begin{array}{l}\text { Exclusión extrema } \\
\text { sinhogarismo }\end{array}$ & $\begin{array}{l}\text { Exclusión extrema } \\
\text { sinhogarismo }\end{array}$ & $\begin{array}{l}\text { Exclusión extrema } \\
\text { sinhogarismo }\end{array}$ \\
\hline
\end{tabular}

Fuente: elaboración propia.

Bloque del Este, hay personas que, aunque en su mayor parte reiniciaron sus vidas en nuestro país con gran precariedad, "salieron adelante». Los factores exclusógenos que convierten a un inmigrante económico en un «sin hogar», en el sentido más extremo, son de orden estructural (ilegalidad jurídica administrativa, política laboral, política de vivienda, política educativa ${ }^{20}$, insuficiencia de recursos sociales, política de inmigración, etc.); de naturaleza familiar o relacional (falta de redes sociales y/o familiares de apoyo, etc.); personal (personalidad, género, edad, raza, nacionalidad, idioma, aptitudes personales, falta de habilidades sociales, descualificación laboral, problemas de salud física y/o mental, trastornos de vida, déficits emocionales, estructura motivacional débil, autoestima baja, etc.), y cultural (choque cultural, "racismo social» (Tezanos y Tezanos, 2003: 230-232) y biológico ${ }^{21}$, etc.).

Los resultados del Quinto recuento nocturno de personas "sin hogar» realizado en la ciudad de Madrid el 24 de febrero de 2010 ponen de manifiesto, en

20. Véase Cachón (2003).

21. Merece especial reconocimiento la creación por el Real Decreto 490/1995, de 7 de abril, del Foro para la Integración Social de los Inmigrantes, dependiente de la Secretaría de Estado de Emigración e Inmigración (Ministerio de Trabajo e Inmigración). 
Gráfico 1. Motivos para verse en la calle según los inmigrantes «sin hogar»

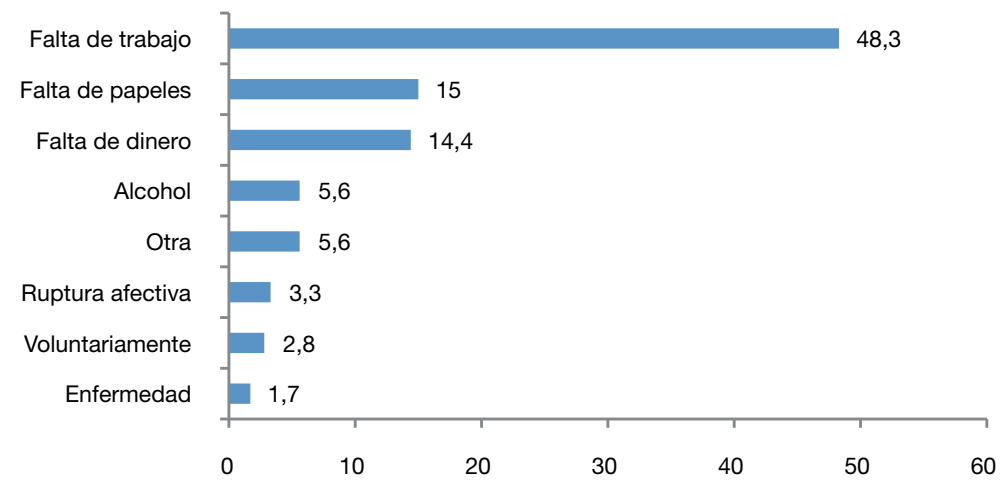

Fuente: Ayuntamiento de Madrid, Quinto recuento nocturno sobre personas «sin hogar», 2010.

boca de los inmigrantes «sin hogar» que fueron entrevistados aquella noche, los motivos que les condujeron a su situación (gráfico 1). Como podemos observar, factores estructurales como la falta de trabajo o su situación de «sin papeles» son claves a la hora de entender sus itinerarios vitales, en relación con lo anterior, su pobreza en términos económicos, así como condicionantes vinculados con rupturas afectivas ${ }^{22}$ y problemáticas de orden personal, como el consumo de alcohol o padecer algún tipo de enfermedad.

\section{La población inmigrante en situación de exclusión social extrema}

Estimar el número de inmigrantes en situación de exclusión extrema en España es muy difícil, dada la ilegalidad administrativa en la que vive un sector de ellos, que, según cálculos de Naciones Unidas, supone aproximadamente el 10\% del total de los empadronados en España (aproximadamente, unas 573.000 personas) (PNUD, 2009).

A este último caso corresponde, básicamente, el perfil del inmigrante «sin techo» / "sin hogar», si bien desde hace varios años se detecta un progresivo incremento de los casos de personas que tuvieron vidas normalizadas en España.

Son mayoritariamente varones jóvenes y de mediana edad (véase el gráfico 2), aunque cada vez hay una mayor presencia de mujeres, menores no acompañados, personas mayores y en edad de jubilación. Analizar las memorias de actividad de algunos dispositivos para población «sin hogar» dispuestos por diversos puntos de la geografía española permite observar la tendencia de los últimos años, así como su perfil sociodemográfico.

22. De hecho, el 64,10\% de los inmigrantes «sin hogar» entrevistados en el Quinto recuento nocturno sobre personas «sin hogar» estaban solteros, divorciados, viudos o separados. 
Gráfico 2. Edades los inmigrantes «sin hogar»
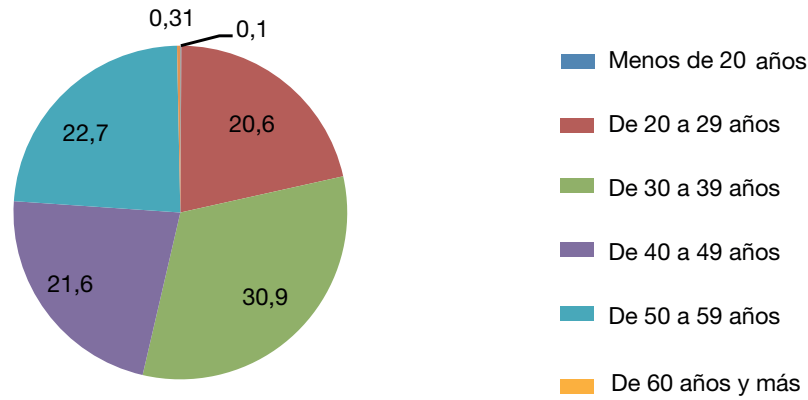

Fuente: Ayuntamiento de Madrid, Quinto recuento nocturno sobre personas «sin hogar», 2010.

En el año 1996, un 8\% de las personas «sin hogar» eran extranjeras; en 2002, la cifra se elevó al 30\% (Cabrera y Malgesini, 2002). Según la Encuesta sobre las personas sin hogar 2005, realizada por el Instituto Nacional de Estadística (INE, 2005), el 48,2\% de los usuarios que acudían a los recursos de atención para esta población eran extranjeros. El grupo mayoritario era el de los africanos $(43,6 \%)$, seguido del de los europeos $(37,5 \%)$ y el de los americanos $(14,0 \%)$.

En los cinco recuentos sobre personas sin hogar realizados anualmente en la ciudad de Madrid desde el año 2006 hasta el 2010, el abanico porcentual de inmigrantes «sin hogar» ha oscilado entre el $48 \%$ y el $55 \%$. También en Madrid, según los datos de la Campaña Municipal contra el Frío 2010-2011, el porcentaje de extranjeros atendidos en estos recursos sobrepasó el 65\% (Ayuntamiento de Madrid, 2011) ${ }^{23}$. Son, fundamentalmente, varones, procedentes del área comunitaria (por la fuerte presencia de rumanos), y cada vez hay un mayor número de mujeres solas, de mujeres con hijos, de jóvenes, de menores no acompañados y de familias completas.

Los países de origen han variado a lo largo de los años. A principios de la década de 1990, en plena crisis de los Balcanes, hubo un número considerable de croatas. En los últimos años, se ha detectado un aumento de ciudadanos de la antigua Europa del Este (Rumanía ${ }^{24}$, Bulgaria, Polonia y Ucrania) y, de un modo constante, se han ido incrementando los marroquíes y los subsaharianos. En menor medida, hay europeos (portugueses, alemanes y franceses) y latinoamericanos (ecuatorianos, peruanos, cubanos y

23. En el dispositivo alternativo de la Campaña contra el Frío 2010-2011 de Madrid, el 70,55\% de los usuarios fueron extranjeros. (Ayuntamiento de Madrid, 2011).

24. Desde hace varios años, la nacionalidad con mayor presencia entre los inmigrantes que acuden, por ejemplo, a los recursos de la Campaña contra el Frio de Madrid es precisamente la de los rumanos. En el Quinto recuento nocturno sobre personas «sin hogar» cerca del 30\% de las personas entrevistadas fueron de dicha procedencia. 
Grafico 3. Campaña Municipal contra el Frío de Madrid. Pabellones Casa de Campo. Datos comparativos de atención. Varios años

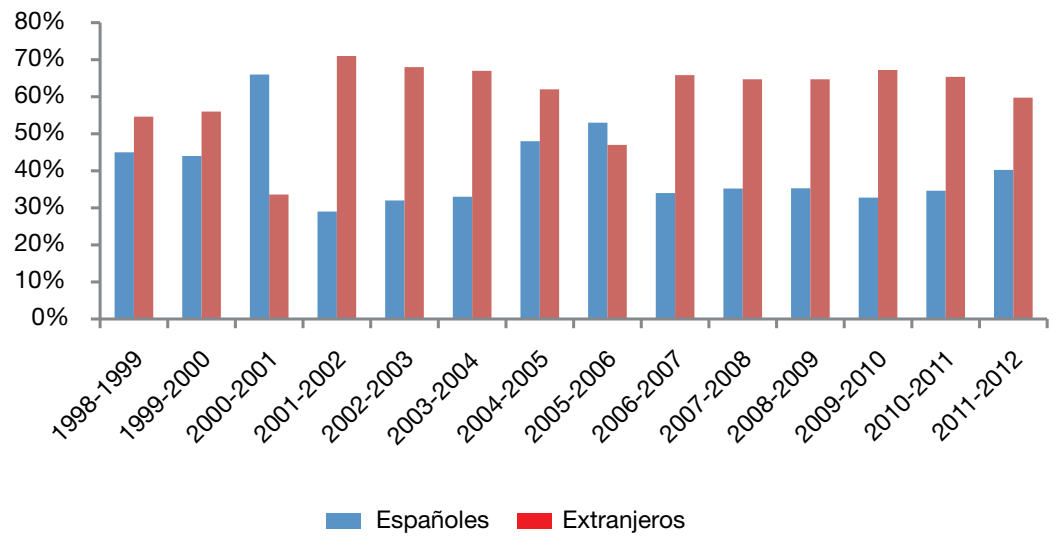

Fuente: Ayuntamiento de Madrid, Campaña Municipal contra el Frío, varios años.

colombianos). Con una anecdótica presencia, tambien encontramos asiáticos y personas de Oceanía.

Pedro Cabrera y Graciela Malgesini plantearon, en el precitado trabajo del año 2002, que, del total de inmigrantes que acudían en España a los servicios de atención para personas «sin hogar», los no comunitarios eran los mayoritarios, existía una limitada presencia de personas de la Unión Europea (sobre todo de Portugal) y un $8 \%$ de subsaharianos. Por nacionalidades e importancia numérica, encontrábamos marroquíes, ecuatorianos, portugueses, rumanos, colombianos, argelinos, búlgaros y ucranianos (Cabrera y Malgesini, 2002: 50-51).

Transcurrida una década desde la presentación de estos datos, se observan ciertos cambios de tendencia, al observar los resultados de la Encuesta sobre las personas sin hogar 2005, así como las memorias de actividad de los últimos trece años de la Campaña Municipal contra el Frío de la ciudad de Madrid (véase el gráfico 3), y las de los últimos once años de los albergues para varones San Juan de Dios de Madrid, Barcelona y Valencia (véase el gráfico 4).

Como podemos observar, salvo en la Campaña Municipal contra el Frío 2000-2001 de Madrid, la población atendida ha sido mayoritariamente extranjera. Las campañas de los años posteriores han confirmado que este programa de atención para población «sin hogar» se ha convertido en un recurso al que acuden mayoritariamente extranjeros, fundamentalmente hasta la Campaña del año 2008-2009 para ciudadanos no comunitarios. A partir de esa fecha, como consecuencia de la incorporación de Rumanía a la Unión Europea, se produce un cambio de tendencia, puesto que se convierten en dispositivos a los que acuden fundamentalmente inmigrantes procedentes del área comunitaria, en su mayor parte procedentes de este país. 
Grafico 4. Campaña Municipal contra el Frío de Madrid. Pabellones Casa de Campo. Datos comparativos de atención. Varios años

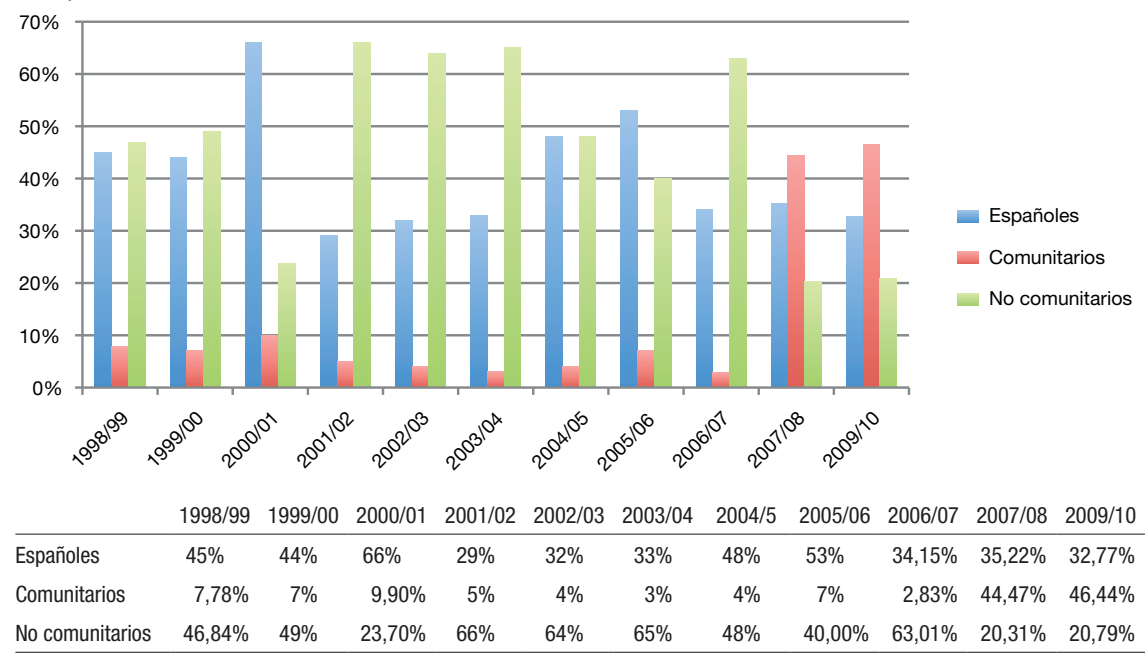

Fuente: Ayuntamiento de Madrid, Campaña Municipal contra el Frío, varios años.

* No están disponibles los datos relativos a la Campaña Municipal contra el Frío 2010-2011.

En los albergues San Juan de Dios de Madrid, Barcelona y Valencia, tal como se desprende de las memorias de actividad de los últimos once años, encontramos una presencia muy significativa de extranjeros (véase el gráfico 5). En Madrid, en el año 2003, los extranjeros superaron a los usuarios de nacionalidad española. En Barcelona son también mayoría, aunque se ha ido produciendo un cierto descenso. En el año 2004, en Valencia, se da un cambio de orientación en la tendencia, pues, tras tres años en los que los usuarios fueron mayoritariamente extranjeros, la presencia de personas nacidas en España pasa al primer lugar. Sin embargo, en el año 2005, se produce en los tres albergues un aumento de extranjeros y resulta especialmente significativo en el caso del de Barcelona. A lo largo de estos años y para estos tres albergues, se confirma que se trata de varones de entre 20 y 39 años y, desde hace varios años, acuden a ellos una mayoría de ciudadanos comunitarios (por la presencia de rumanos, polacos y búlgaros), seguidos de los no comunitarios (africanos y americanos).

A la luz de lo expuesto, cabe plantear que la internacionalización de la exclusión social extrema en España es una realidad. El fenómeno se dispara a finales de la década de 1990. En los últimos años, se detecta, en las calles de las principales ciudades españolas y en los recursos de atención para esta población, un creciente número de extranjeros que, por su problemática, son personas «sin hogar» crónicas. Respecto al futuro de este fenómeno sociológico, no es fácil precisar hipótesis de futuro rigurosas y contrastadas, habida cuenta de los elementos estructurales que intervienen en su evolución. 
Sobre lo que no parece haya dudas es que en los últimos años ha aumentado, en general, la población «sin hogar» en nuestro país, tal como apuntaron en febrero de 2010 las personas entrevistadas en el Quinto recuento nocturno sobre personas "sin hogar», así como la opinión pública española consultada en la Encuesta de Tendencias Sociales 2010 del GETS (véanse los gráficos 6 y 7). Resulta destacable que al $43,19 \%$ de los entrevistados en dicha encuesta le incomodaba la presencia de personas "sin hogar» en la ciudad o municipio donde pasaba el día habitualmente, sin embargo, en su mayor parte $(69,49)$ estimaba que las autoridades deberían apoyar y ayudar en todo lo que se pueda a estas personas, frente a un escueto $1,50 \%$ que planteaba que era necesario obligarlas a retirarse de la calle, incluso por la fuerza (GETS, 2010).

\section{Referencias bibliográficas}

Ayuntamiento de Madrid (1998, 1999, 2000, 2001, 2002, 2003, 2004, 2005, 2006, 2007, 2008, 2009, 2010, 2011). Informes sobre la Campaña Municipal contra el Frío. Madrid: Dirección General de Servicios Sociales. Departamento de Samur Social. Personas Sin Hogar e Inserción Social.

Bosch-MedA, J. (2010). «Homelessness among Migrants in Spain, European». Journal of Homelessness, 4, 139-154.

CABRera, Pedro (2000). Mujeres «sin hogar» en España. Informe Nacional. FEANTSA.

Cabrera, Pedro y Malgesini, Gabriela (2002). Inmigrantes y sinhogarismo en España. Informe Nacional 2001-2002. FEANTSA.

CACHÓN, Lorenzo (2003). Inmigrantes jóvenes en España: Sistema educativo y mercado de trabajo. Madrid: Instituto de la Juventud.

Carrasco, Concha e Izquierdo, Antonio (2005). «Flujos, tendencias y signos de instalación de los extranjeros en España». Papeles de Economía Española, 104, 92-122.

Cavalcanti, Leonardo (2008). «Negocios étnicos: importación y repercusiones de una categoría». En: Santamaría Lorenzo, Enrique (coord.). Retos epistemológicos de las migraciones transnacionales. Barcelona: Anthropos, 217-236.

Edgar, Bill; Doherty, Joe y Meert, Heerk (2004). Immigration and Homelessness in Europe. Bristol: Policy Press.

EDIS (2004). Realidad social de las mujeres sin techo, prostitutas, ex reclusas y drogodependientes. Madrid: Ministerio de Trabajo y Asuntos Sociales. Instituto de la Mujer, 7-11.

FAO (2011). El estado de la inseguridad alimentaria en el mundo: ¿Cómo afecta la volatilidad de los precios internacionales a las economías nacionales y la seguridad alimentaria? [en línea]. <http://www.fao.org/publications/sofi/es/>.

FEANTSA (2004). Inmigration and Homelessness in Europe. Bristol: Policy Press.

- (2010). "Homelessness and migration in Europe: finding responses». Homeless in Europe, verano [en línea]. <http://www.feantsa.org/files/freshstart/Communications/Homeless\%20in\%20Europe\%20EN/PDF_2010/Homeless_in_Europe_ Summer2010_EN_Final.pdf>.

GETS (1997). Estudio Delphi sobre tendencias científico-tecnológicas en España 1997. Madrid: Fundación Sistema.

- (2003). Estudio Delphi sobre tendencias cientifico-tecnológicas 2002. Madrid: Fundación Sistema. 
GETS (2006). Tendencias cientifico-tecnológicas 2006. Madrid: Fundación Sistema. Material de trabajo.

- (2008). Condiciones laborales de los trabajadores inmigrantes en España. Madrid: Fundación Sistema.

- (2010). Encuesta de tendencias sociales. Madrid: UNED / Fundación Sistema.

Guerra, Alfonso y Tezanos, José Félix (eds.) (2008). La inmigración y sus causas: VI Encuentro de Salamanca. Madrid: Fundación Sistema.

Instituto Nacional de Estadística (2005). Encuesta sobre las personas sin hogar [en línea]. <http://www.ine.es/prensa/np398.pdf>.

- (2008). Encuesta nacional de inmigrantes, 2007 [en línea]. <http://www.ine.es/jaxi/ menu.do?type $=$ pcaxis $\&$ path $=\% 2 \mathrm{Ft} 20 \% 2 \mathrm{Fp} 319 \&$ file $=$ inebase $>$.

- (2011a). Avance del Padrón municipal a 1 de enero de 2011. Datos provisionales, 4 de abril de 2011 [en línea]. <http://www.ine.es/prensa/np648.pdf>.

- (2011b). Encuesta de población activa [en línea]. Tercer trimestre 2011. <http:// www.ine.es/daco/daco42/daco4211/epa0310.pdf>-

- (2011c). Avance del Padrón municipal a 1 de enero de 2012 [en línea]. Nota de prensa, 19 de abril de 2012. <http://www.ine.es/jaxi/menu.do?type=pcaxis\&path=/ t20/e245/\&file=inebase $>$.

IzQuierdo, Antonio (2007). «Panorama de la inmigración en la España del 2006». En: Inmigración: crecimiento económico e integración social, 2007, 77-100.

López de Lera, Diego Constantino e IzQuierdo, Antonio (2000). «La huella demográfica de la población extranjera en España». Sistema, 175-176, 181-200.

LuQue SAlCEdA, Carmen (2003). «La mujer sin hogar: realidades y reflexiones». Cuadernos de Trabajo Social, 16, 249-264.

Lurbe Kàtia y SolÉ, Carlota (2006). Inmigración comunitaria: ¿Discriminación inversa? Barcelona: Anthropos.

Muñoz, Manuel; VÁzquez, Carmelo y Vázquez, José Juan (2003). Los límites de la exclusión: Estudio sobre los factores económicos, psicosociales y de salud que afectan a las personas sin hogar en Madrid. Madrid: Tempora, 19.

Noya, Javier e IzQuierdo, Antonio (1999). «Lugares migratorios: Una propuesta teórica y metodológica para el análisis de la integración social de los inmigrantes». Migraciones, 6, 19-42.

OIT (2010). Intensificar la lucha contra el trabajo infantil: Informe global sobre trabajo infantil 2010 de la OIT [en línea]. Ginebra. <http://www.ilo.org/wcmsp5/ groups/public/@dgreports/@dcomm/documents/publication/wcms_126694. pdf $>$.

- (2011). Niños en trabajos peligrosos: Lo que sabemos, lo que debemos hacer. Ginebra.

PNUD (2009). Informe sobre desarrollo humano 2009. Superando barreras: movilidad $y$ desarrollo humanos [en línea]. <http://hdr.undp.org/es $>$.

- (2010). Informe sobre desarrollo humano 2010. La verdadera riqueza de las naciones: Caminos al desarrollo humano [en línea]. <http://hdr.undp.org/es/informes/ mundial/idh2010/>.

- (2011). Informe sobre desarrollo humano 2011. Sostenibilidad y equidad: Un mejor futuro para todos [en línea]. <http://hdr.undp.org/en/media/HDR_2011_ES_ Complete.pdf $>$.

Sánchez Morales, Ma Rosario (1999). «Las mujeres “sin hogar” en la España de final de siglo". A distancia, 1, 166-172.

- (2006). «La internacionalización de la exclusión social extrema en España: Tendencias y escenarios de futuro». Sistema, 190-191, 395. 
Sánchez Morales, Ma Rosario y Tezanos Vázquez, Susana (2004). "Los inmigrantes "sin hogar" en España: Un caso extremo de exclusión social». Revista del Ministerio de Trabajo y Asuntos Sociales, 55, 50.

Solé, Carlota y Parella, Sonia (2005). Negocios étnicos: Los comercios de los inmigrantes no comunitarios en Cataluña. Barcelona: Fundación CIDOB.

- (2006). «Mujeres inmigrantes no comunitarias en el mercado de trabajo español». Sistema, 190-191, 194.

Tezanos, José Félix (1998). Tendencias en exclusión social en las sociedades tecnológicas avanzadas. Madrid: Sistema, 11.

- (2001). La sociedad dividida. Madrid: Biblioteca Nueva, 140-147.

Tezanos, José Félix y Tezanos, Sergio (2003). «Inmigración y exclusión social». Papeles de Economía Española, 98, 230-232.

Thomas, William I. y ZnANiecki, Florian (2004). El campesino polaco en Europa y América. Madrid: Centro de Investigaciones Sociológicas y Boletín Oficial del Estado.

United Nations (2009). Trends in International Migrant Stock: The 2008 Revision [en línea]. Department of Economic and Social Affairs Population Division. <http:// esa.un.org/migration/p2k0data.asp >. 
